NOTE AND CORRESPONDENCE

\title{
Comparisons of Warm Cloud Properties Obtained from Satellite, Ground, and Aircraft Measurements during APEX Intensive Observation Period in 2000 and 2001
}

\author{
Takashi Y. NAKAJIMA \\ Department of Network and Computer Engineering, School of Engineering II, Tokai University, Tokyo, Japan \\ Akihiro UCHIYAMA \\ Meteorological Research Institute, Tsukuba, Japan \\ Tamio TAKAMURA, Naoya TSUJIOKA \\ Center for Environmental Remote Sensing, Chiba University, Chiba, Japan \\ Toshihiko TAKEMURA \\ Research Institute for Applied Mechanics, Kyushu University, Fukuoka, Japan \\ and \\ Teruyuki NAKAJIMA \\ Center for Climate System Research, University of Tokyo, Kashiwa, Japan \\ (Manuscript received 10 November 2003, in final form 7 September 2005)
}

\begin{abstract}
Cloud microphysical properties derived from satellite data during December 2000 and April 2001, Asian Atmospheric Particulate Environment Change Studies (APEX) Intensive Observational Period (IOP), are compared with ground and aircraft measurements. The target clouds are marine stratus and stratocumulus. They appeared over the Amami-Oshima Island, and off the south coast of Kyushu island. The principal goals of the comparison are to understand the characteristics of data obtained from each observing platform, and investigate the potentiality of synergistic use of multi platform data. The liquid water paths obtained from satellite (MODIS) observation by using the GLI cloud retrieval algorithm
\end{abstract}

Corresponding author: Takashi Y. Nakajima, Department of Network and Computer Engineering, School of Engineering II, Tokai University, 2-28-4, Tomigaya, Shibuya-ku, Tokyo, 151-0063, Japan.

E-mail: nkjm@yoyogi.ycc.u-tokai.ac.jp

(C) 2005, Meteorological Society of Japan 
were compared with the ground-based measurements (microwave radiometer). The correlation coefficient and the root mean square error between ground and satellite liquid water path was 0.87 and $61.9 \mathrm{~g} / \mathrm{m}^{2}$. The satellite-retrieved cloud effective radius agreed with those from the aircraft measurements (FSSP) around the top of the cloud.

\section{Introduction}

The Intergovernmental panel on Climate Change (IPCC) 2001 reported that the aerosolcloud interaction process is one of the largest uncertainties in the climate change study (IPCC 2001). It emerged that aerosol in the atmosphere can influence the Earth radiation budget through changes in the cloud optical and microphysical properties by several effects (e.g., Twomey et al. 1984; Coakley et al. 1987; Radke et al. 1989). Therefore, it is expected that progress in cloud and aerosol microphysical modeling in the climate model will contribute to improving the accuracy of future climate predictions. Observation data will be important for detecting signs of the aerosol indirect effects in the actual atmosphere and for developing aerosol and/or cloud models that simulate this effect. Particularly, the vertical and horizontal surveys of cloud properties in turbid atmosphere environment are required as is the case with clean atmosphere environment. The Asian Atmospheric Particulate Environment Change Studies (APEX) intensive observation periods (IOP) were initiated in December 2000 (hereafter, APEX-E1) and April 2001 (AEPX-E2), to observe distributions and properties of cloud and aerosol, around the East China Sea where both naturally occurring and artificial aerosols are seeded from the Asian continent. Among these IOPs, the APEX-E2 (Nakajima et al. 2003) was performed together with Asian Pacific Regional Aerosol Characterization Experiment (ACE-Asia)'s IOP (Huebert et al. 2003). Observations were made from ground stations, aircrafts and Earth observing satellites.

The comparison between satellite remote sensing versus ground-based measurements can provide a baseline for estimating errors in the satellite products, and the comparisons between satellite remote sensing versus aircraft in situ measurements are needed to quantify the uncertainties in satellite remote sensing (Dong et al. 2002). It must be conducted care- fully because of spatial and temporal differences and, sometimes, the different observing principles between the different observing sensors. When we understand the characteristics of results obtained from each observing systems, we can go to the next research stages such as validation of satellite-retrieved parameters by using ground-based and/or airborne data, and multilateral observations that conduct minute investigations of the observing targets. During the long history of the satelliteborne cloud remote sensing, the numbers of previous studies on the comparison of the cloud optical and/or microphysics obtained from different observing systems gradually increased (e.g., Platnick and Twomey 1994; Hayasaka et al. 1994; Platnick and Valero 1995; Han et al. 1995; Nakajima and Nakajima 1995; Kuji et al. 2000; Kawamoto et al. 2001; Dong et al. 2002). However, every chance of the collocated and coincident observations from satellite, groundbased, and airborne systems is still valuable and important, because the cloud features will vary according to every location, area, and season. For instance, Dong et al. (2002) made comparisons of stratus cloud propertied obtained from ground measurements, Geostationary Operational Environmental Satellite (GOES) remote sensing, and aircraft in situ measurements at the Atmospheric Radiation Measurement (ARM) Southern Great Plains (SGP) site during the IOP in March 2000. They got results that the mean and standard deviation of the liquid water path differences, between ground measurements and satellite remote sensing was $4 \% \pm 31.6 \%$.

In this paper, the comparisons of the liquid water paths obtained from ground measurements and satellite observations, the effective radii of cloud particles (hereafter, cloud effective radii) obtained from aircraft measurements and satellite observations around the East China Sea region performed during the APEX intensive observation periods in December 2000 and April 2001 are shown. 


\section{Data sources}

\section{a. Satellite observation data and retrieval algorithm}

We retrieved cloud properties, such as optical thickness $\left(\tau_{c \_ \text {modis }}\right)$, effective radius $\left(r_{e_{-} \text {modis }}\right)$, liquid water path ( $\left.L W P_{\text {modis }}\right)$ and cloud top temperature $\left(T_{c_{-} \text {modis }}\right)$ from the Moderate Resolution Imaging Spectroradiometer (MODIS) aboard the Terra satellite. Since the Terra is the sun-synchronous polar orbit satellite which crosses the equator about mid morning local time, the MODIS observes the Earth targets nearly once a day in the daytime. The spatial resolution of most MODIS channels was one kilometer at nadir looking. This resolution is wider than that from most ground observations and aircraft measurements, so it is important to choose homogeneous targets when one compares satellite-measured values with ground or aircraft values. The sub-pixel geolocation accuracy of the MODIS observation is approximately fifty meters at nadir (Wolfe et al. 2002). The salient features of the MODIS instrument have been described by King et al. (1992).

The primary observation target of our IOPs is the APEX ground measurement supersite on Amami-Oshima Island in the East China Sea. A near real time satellite data analysis system was developed for the APEX IOPs. We get the level $1 \mathrm{~B}$ radiance data to the data analysis system via internet installed in the National Institute of Environmental Study (NIES) in Tsukuba, Japan, and retrieved cloud properties using non-absorbing shortwave wavelength $(\lambda=0.865 \mu \mathrm{m})$, absorbing near-infrared $(3.7 \mu \mathrm{m})$, and infrared $(10.8 \mu \mathrm{m})$ bands of MODIS. We used a retrieval algorithm developed for general imagers, named Comprehensive Analysis Program for Cloud Optical Measurements (CAPCOM) (Nakajima and Nakajima 1995; Kawamoto et al. 2001). In summary, the moderately large imaginary indices of refraction $m_{i}\left(\sim 10^{-3}\right)$ of liquid water in the $3.7-\mu \mathrm{m}$ band make the observed radiance sensitive to the cloud particle size $\left(r_{e}\right)$, and a small imaginary index of refraction $\left(\sim 10^{-7}\right)$ in the $0.865-\mu \mathrm{m}$ band sensitive to cloud optical thickness $\left(\tau_{c}\right)$. Because the 3.7- $\mu \mathrm{m}$ band includes both the reflected solar component and the undesired emitted thermal component, the cloud top temperature obtained from the $10.8-\mu \mathrm{m}$ band is used to eliminate thermal component from the $3.7-\mu \mathrm{m}$ radiances. Since the $0.865-\mu \mathrm{m}$ band and 3.7- $\mu \mathrm{m}$ band have the small dependence of $r_{e}$ and $\tau_{c}$, respectively, $\tau_{c}$ and $r_{e}$ should be retrieved simultaneously. We use a Newton method to retrieve $\tau_{c}$ and $r_{e}$ from satellite measured radiances with look-up-tables of the simulated measured radiances at the possible $\tau_{c}$, $r_{e}$ and the scan geometries in the remote sensing such as satellite and solar zenith angles, azimuth angle. The expected retrieval error is less than a few percent for $\tau_{c}$ and ten percent for $r_{e}$ under the cloud conditions as $\tau_{c}>2$, $r_{e} \sim 10 \mu \mathrm{m}$ (Nakajima and Nakajima 1995).

\section{b. Ground measurement data}

The APEX ground observation supersite was located at latitude and longitude of $(28.44 \mathrm{~N}$, 129.70 E), the coast of Amami-Oshima. The liquid water paths $(L W P)$ were retrieved from the brightness temperatures at 23.8 and $31.4 \mathrm{GHz}$ taken every seven-minutes using a microwave radiometer (Radiometrics, WVR1100) on the site. Additionally, a skycamera took snapshots of the upper hemisphere every one-minute during the daytime to monitor the cloud amounts in whole sky. The skycamera photos and retrieved cloud amounts were useful to identify the homogeneity of the clouds. A large cloud amount, for instant, is expected to be an evidence of appropriate collocations of cloud observations.

The mean temporal and spatial difference between MODIS and ground observations were a few minute and one kilometer, respectively. This temporal and spatial difference is due to the coarse time step of the WVR1100 measurements and the inhomogeneous cloud over the ground station. Thus, it will be better to present the results by the mean value of temporal (for the ground measurements) and spatial (for the satellite measurements) domain and their standard deviations.

\section{c. Aircraft measurement data}

Under the framework of collaborative research with the Commonwealth Scientific and Industrial Research Organization (CSIRO), the Airborne Research Australia (ARA) Beechcraft Super King Air (hereafter, B200) was operated around the East China Sea for ten days during the APEX-E2 period in 2001, to observe stratocumulus and cumulus clouds, cloud lifecycle, 
frontal structure, and aerosols with instrument that measure thermodynamics, particles, and radiation. Among these flights, nearly collocated and coincident observations of stratocumulus clouds with a MODIS overpass was established on the morning flight of April 27, 2001. The Particle Measurement System (PMS) Forward Scattering Spectrometer Probe (FSSP) on B200 measured the cloud droplet concentration spectrums. The cloud effective radii from the top to the bottom of the stratocumulus clouds that appeared off the coast of $\mathrm{Ka}$ goshima, were obtained from the FSSP cloud measurements.

\section{Results and discussion}

a. Satellite observation and ground measurement

Figure 1 illustrates the liquid water paths obtained from the Terra MODIS (LWP_modis) and the microwave radiometer placed on the ground station $\left(L W P_{-w v r 1100}\right)$ during the APEXE1 and APEX-E2 IOP. LWP_modis is calculated from cloud optical thickness $\tau_{c_{-} \text {modis }}$ and cloud effective radius $r_{e_{-} \text {modis }}$ using the following equation,

$$
L W P_{\_} \text {modis }=\frac{2}{3} \tau_{c \_ \text {modis }} \cdot r_{e_{\_} \text {modis }} .
$$

Some statistic calculations were needed due to the different field-of-view of WVR1100 (approximately 5 degrees beam width) and MODIS (one kilometers spatial resolution at nadir), and horizontally inhomogeneous structure of the targets over the ground observation site. This is one of the general problems of the comparisons of results obtained from different platforms. Ichoku et al. (2002) discussed this issue for the MODIS aerosol validations by use of the MODIS results with a coarse pixel size of $10 \times 10 \mathrm{~km}$ and skyradiometer results from ground. They computed statistic values from $50 \times 50 \mathrm{~km}$ spatial subsets for the MODIS and one-hour subsets for skyradiometer. We applied this idea to our results. The $L W P_{-}$modis and

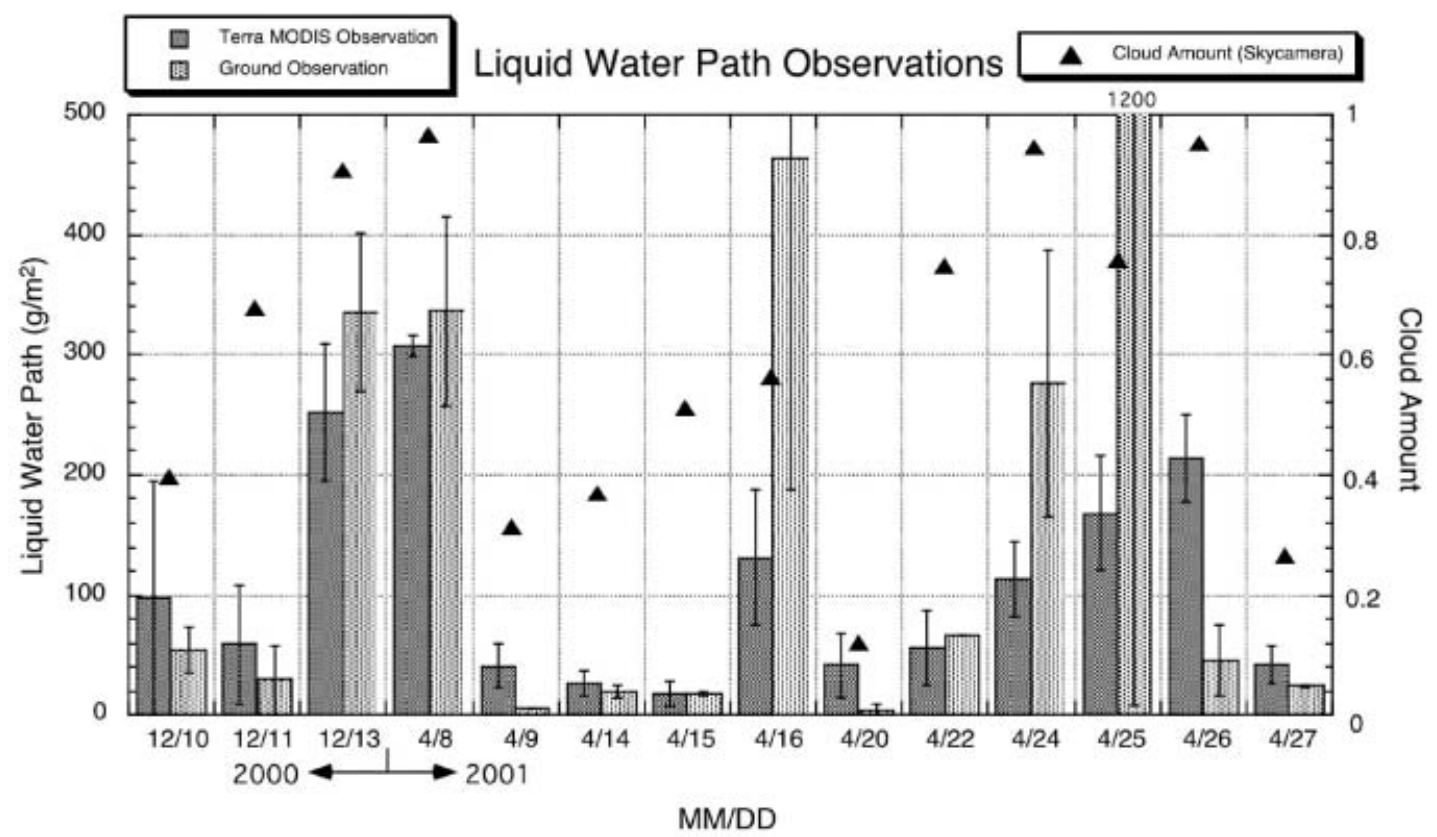

Fig. 1. Nearly collocated and coincident comparison of the liquid water paths obtained from MODIS $\left(L W P_{-}\right.$modis $)$and microwave radiometer placed on the ground station $\left(L W P_{\_}\right.$wvr1100) with the cloud amounts. $L W P_{-}$modis were the mean values of the MODIS pixels included in a 5 -km radius from the ground station. The $L W P_{-w v r 1100}$ were mean values of the WVR1100 measurements included in a fifteen minute from the MODIS overpass time. The corresponding error bars at each $L W P_{-}$modis and $L W P_{-w v r 1100}$ plot denote the standard deviations. 
$L W P_{\text {wvr } 1100}$ in Fig. 1 are the mean values of the MODIS pixels included in a $5-\mathrm{km}$ radius from the ground station (spatial subset) and of the WVR1100 measurements included in a fifteen minutes from the MODIS overpass time (temporal subset), respectively. The corresponding error bars at each $L W P_{-}$modis and $L W P_{-}$wor 1100 plots denote standard deviation of the subset values. The cloud amount retrieved by skycamera is also plotted in Fig. 1.

Since the APEX-E1 in 2000 was the test installation period, the comparison can be made only days of 10,11 , and 13 in 2000 . During the APEX-E2 in 2001, the high-level cumulus clouds that had a very low cloud top temperature below the freezing point accompanied with rainfalls prevented the successful retrieval of $L W P_{\text {modis }}$ on the 17 and 21 in April. On days $12,13,19$ and 23 , no clouds appeared over the ground site, and no MODIS observations were available on days 10,11 , and 18 . Therefore, the comparisons were made on the day of $8,9,14$, $15,16,20,22,24,25,26$, and 27. In Fig. 1, we found that the difference of the liquid water path is larger on 16, 24, 25, and 26 in April 2001. Before calculating their correlation, we made the quality control of each data. The cloud amounts estimated from the skycamera, weather information, and relative humidity data obtained by Met3 system will be useful for the quality control. Skycamera photos on days 16, 24, 25, and 26 in Fig. 2 showed that the clouds seemed horizontally homogeneous enough to regard the observing domains (field of view) of MODIS (1 km) and WVR1100 were collocated. However, the $L W P_{-w v r 1100}$ were much larger than the $L W P_{-}$modis on the days 16 , 24 , and 25. A possible reason for these inconsistencies is the moisture in the WVR1100 equipment (or the wet window of WVR1100). Therefore these data are removed from the comparisons.

Figure 3 showed the correlation between

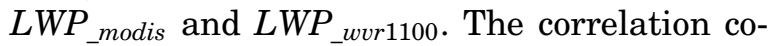
efficient was $R=0.87$. The $R$ can be located around 0.56 to 0.97 at significant level of $95 \%$. The root mean square error between ground and satellite liquid water path was $61.9 \mathrm{~g} / \mathrm{m}^{2}$.

Dong et al. (1998) suggested the parameterization method to estimate cloud effective radius $r_{e-p a r a m}$. from ground measurements by polynomial function of $L W P_{\_w r 1100}, \gamma$, and $\mu_{0}$ :

$$
\begin{aligned}
r_{e_{-} \text {param }}= & -2.07+2.49 L W P_{\_w v r 1100} \\
& +10.25 \gamma-0.25 \mu_{0} \\
& +20.28 L W P_{-w v r 1100 \gamma} \\
& -3.14 L W P_{-w v r 1100} \mu_{0},
\end{aligned}
$$

where the unit of $L W P_{-w v r 1100}$ is $\left(100 \mathrm{~g} / \mathrm{m}^{2}\right), \mu_{0}$ the cosine of solar zenith angle. $\gamma$ is the transmission ratio defined as

$$
\gamma=\frac{F(\text { cloudy })}{F(\text { clear })}
$$

where $F($ cloudy) is the measured cloudy sky downward solar fluxes at the surface measured by phyranometer, $F$ (clear) the inferred flux that would be recorded by the phyranometer if there were no clouds. We estimated $F$ (clear) at the observation time by finding the largest pyranometer data from the days during the IOP. If the $\gamma=0.5$ includes $10 \%$ error, the estimation errors in $r_{e \text { param. }}$ are approximately $0.8 \mu \mathrm{m}$ and $1.5 \mu \mathrm{m}$ for the $L W P_{w v r 1100}=30 \mathrm{~g} / \mathrm{m}^{2}$ and $100 \mathrm{~g} / \mathrm{m}^{2}$, respectively. Once $r_{e_{-} \text {param. was }} \mathrm{ob}-$ tained, then the cloud optical thickness $\tau_{c_{-} \text {param }}$. was calculated by Eq. (1) with $L W P_{\text {wur1100 }}$ and $r_{e-p a r a m}$. We applied this polynomial function

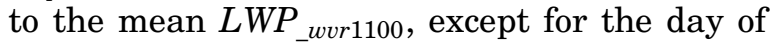
April 20, 2001 due to the pyranometer trouble. Figure 4 illustrates the correlation between the effective radius obtained from MODIS $r_{e_{-} \text {modis }}$ and $r_{e_{-} \text {param. }}$ [Fig. 4(a)], between the cloud optical thickness from MODIS $\tau_{c_{-} \text {modis }}$ and $\tau_{c_{-} \text {param. }}$. [Fig. 4(b)], respectively. The error bars in each correlation mean the standard deviation of the MODIS spatial subsets (x axis), and expected errors due to the $10 \%$ error in $\gamma$ estimation (y axis). The correlation coefficients are 0.63 and 0.79 for the cloud effective radius and cloud optical thickness, respectively. Generally, $\tau_{c \_ \text {modis }}$ are larger than $\tau_{c_{-} \text {param. }}$, whereas $r_{e_{-} \text {modis }}$ are larger or smaller than $r_{e_{-} \text {param. }}$. If we assume the $10 \%$ underestimation of the $F$ (clear) (over estimation of the $\gamma$ ) due to the imperfect of the clear-sky assumption such as cloud contaminations, each plot moves to the lower limit of the error bars in Fig. 4(a) and higher limit in Fig. 4(b).

\section{b. Satellite observations and aircraft measurement on April 27}

On April 27, 2001, the area off the south coast of Kagoshima, Kyushu Island (north-east 


\begin{tabular}{|c|c|c|c|c|}
\hline $\begin{array}{l}\text { Day } \\
\text { C.A. } \\
\text { R.H. }\end{array}$ & $\begin{array}{c}\text { Dec. } 10,2000 \\
0.39 \\
68 \%(F \rightarrow C)\end{array}$ & $\begin{array}{c}\text { Dec. } 11 \\
0.67 \\
55 \%(C \rightarrow C)\end{array}$ & $\begin{array}{c}\text { Dec. } 13 \\
0.91 \\
63 \%(C \rightarrow C)\end{array}$ & \\
\hline $\begin{array}{l}\text { MODIS } \\
\text { WVR1100 }\end{array}$ & & & & $\begin{array}{l}\text { Note: } \\
\text { C.A.:Cloud Amount } \\
\text { R.H.:Relative } \\
\text { Humidity } \\
\text { F: Fair, } \\
\text { C: Cloudy }\end{array}$ \\
\hline $\begin{array}{l}\text { Day } \\
\text { C.A. } \\
\text { R.H. }\end{array}$ & $\begin{array}{c}\text { Apr. 8, } 2001 \\
0.97 \\
84 \%(C \rightarrow R)\end{array}$ & $\begin{array}{c}\text { Apr. } 9 \\
0.26 \\
70 \%(F \rightarrow R)\end{array}$ & $\begin{array}{c}\text { Apr. } 14 \\
0.37 \\
47 \%(\mathrm{~F} \rightarrow \mathrm{F})\end{array}$ & $\begin{array}{c}\text { Apr.15 } \\
0.51 \\
57 \%(F \rightarrow F)\end{array}$ \\
\hline MODIS & & & & \\
\hline WVR1100 & & & & \\
\hline $\begin{array}{l}\text { Day } \\
\text { C.A. } \\
\text { R.H. }\end{array}$ & $\begin{array}{c}\text { Apr. } 16 \\
0.57 \\
87 \%(R \rightarrow C)\end{array}$ & $\begin{array}{c}\text { Apr. } 20 \\
0.12 \\
55 \%(\mathrm{~F} \rightarrow \mathrm{F}) \\
\end{array}$ & $\begin{array}{c}\text { Apr. } 22 \\
0.76 \\
70 \%(F \rightarrow F)\end{array}$ & $\begin{array}{c}\text { Apr. } 24 \\
0.92 \\
80 \%(R \rightarrow C)\end{array}$ \\
\hline MODIS & & & & \\
\hline WVR1100 & & & & \\
\hline $\begin{array}{l}\text { Day } \\
\text { C.A. } \\
\text { R.H. }\end{array}$ & $\begin{array}{c}\text { Apr. } 25 \\
0.77 \\
90 \%(R \rightarrow C)\end{array}$ & $\begin{array}{c}\text { Apr. } 26 \\
0.93 \\
67 \%(C \rightarrow C)\end{array}$ & $\begin{array}{c}\text { Apr. } 27 \\
0.26 \\
66 \%(\mathrm{~F} \rightarrow \mathrm{F})\end{array}$ & \\
\hline MODIS & & & & \\
\hline WVR1100 & & & & \\
\hline
\end{tabular}

Fig. 2. Skycamera photo, cloud amount (C.A.), relative humidity (R.H.), and the weather information at 09:00 and 15:00 JST measured at the ground site in Amami-Oshima Island (28.44 N, $129.70 \mathrm{E})$. C.A. are retrieved from skycamera photos, R.H. are obtained by meteorological measurement system (Met3). F, C, and R in the weather information denote fair, cloudy, and rain, respectively.

of Amami-Oshima Island) was just on the edge of the high-pressure system. At the same time, a weak front was developing at the south part of the China continent. Therefore, southerly humid winds flow along the edge of the highpressure system. A optically thick stratocumulus cloud system that has horizontal dimension approximately $120 \times 120$ kilometers appeared. 


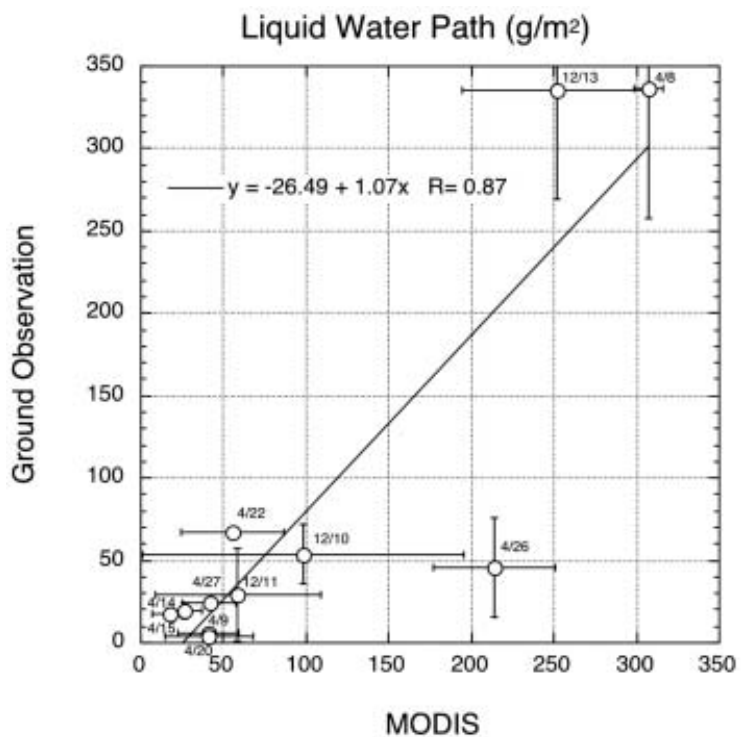

Fig. 3. Correlation of the liquid water paths obtained from MODIS $\left(L W P_{\text {modis }}\right)$ and Ground observations $\left(L W P_{-w v r 1100}\right)$. The number printed near by each circle on the figure indicated the month/day of each observation.
B200 and MODIS observed this cloud nearly collocated and coincidently. Figure 5 illustrated cloud optical thickness over this area obtained from the MODIS retrieval. The B200 took off at 00:34:00 UTC, reached the cloud area at 01:30:00 UTC, and started observing the target clouds. Figure 6 shows the time series of the cloud in situ measurements by FSSP on B200 from 02:16:00 to 02:23:00 UTC (11:16:00 to 11:23:00 JST) time domain, and MODIS values of the cloud optical thickness and cloud effective radius at the corresponding position. Since the wind speed was around $3 \mathrm{~m} / \mathrm{s}$ during this comparison, the cloud can move approximately 200 700 meters during the time difference of B200 and MODIS measurements. The B200 descended from $2250 \mathrm{~m}$ to $1250 \mathrm{~m}$ during this time period [Fig. 6(b)] so that a direct comparison of the cloud effective radii between the B200 and MODIS at the cloud top was achieved exactly at 02:18:00 UTC. The MODIS-retrieved cloud optical thickness $\tau_{\text {c_modis }}$ is also shown in the upper part of Fig. 6(a). The shadowed area in Fig. 6 indicates that the B200 was observing the inside of the stratocumulus clouds.

The cloud effective radius obtained from MODIS and FSSP agreed well at the cloud top
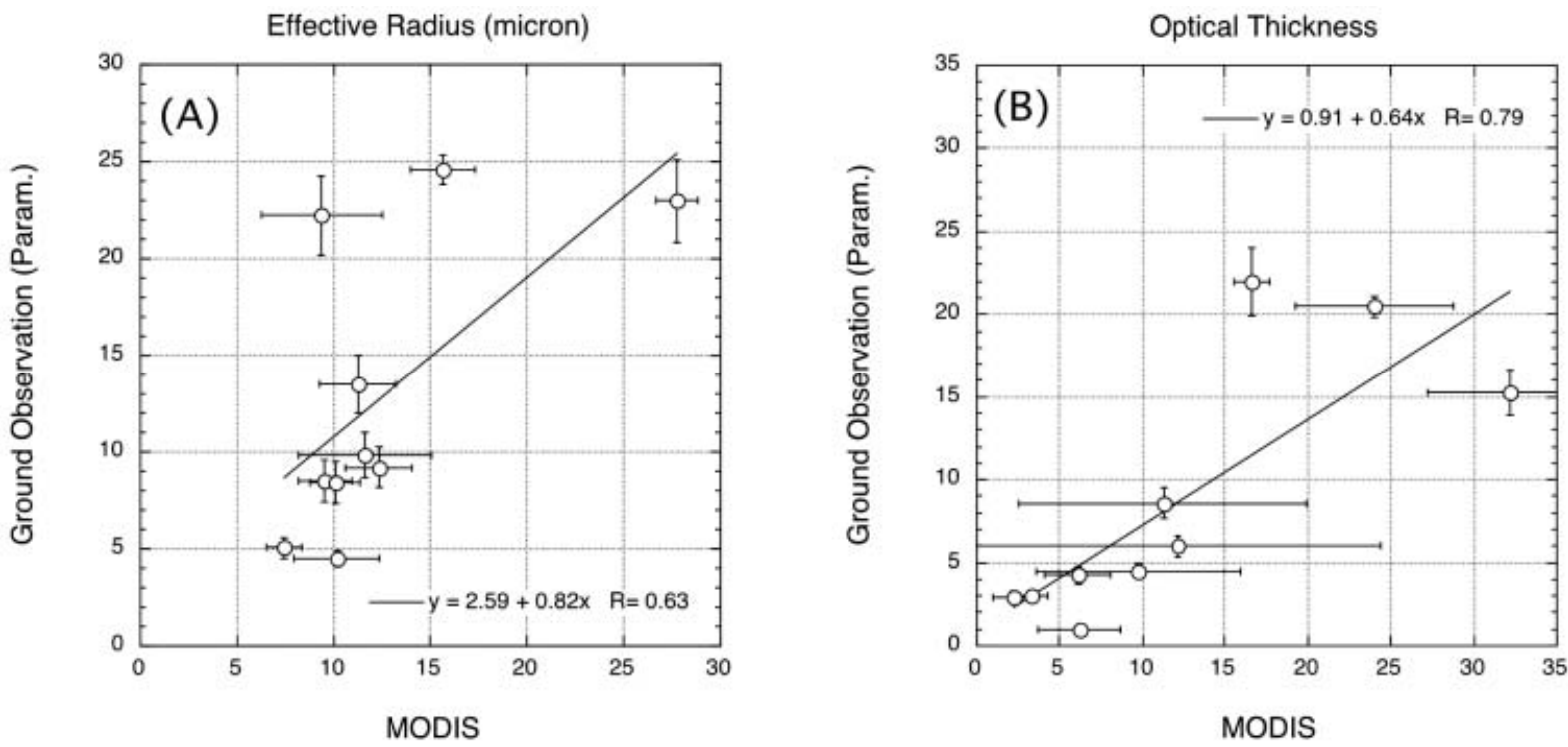

Fig. 4. Correlation between the effective radius obtained from MODIS $\tau_{c \_p a r a m}$. and $r_{e_{-}}$param. (a), between the cloud optical thickness from MODIS $\tau_{c_{-} \text {modis }}$ and $\tau_{c_{-} \text {param. }}$ (b). $r_{e_{-} \text {param }}$. were estimated by us of Dong's (Dong et al. 1998) parameterization of Eq. (2), then $\tau_{c_{-} \text {param. }}$ were calculated by Eq. (1) with $L W P_{-} w v r 1100$ and $\tau_{c_{-} \text {param. }}$. 


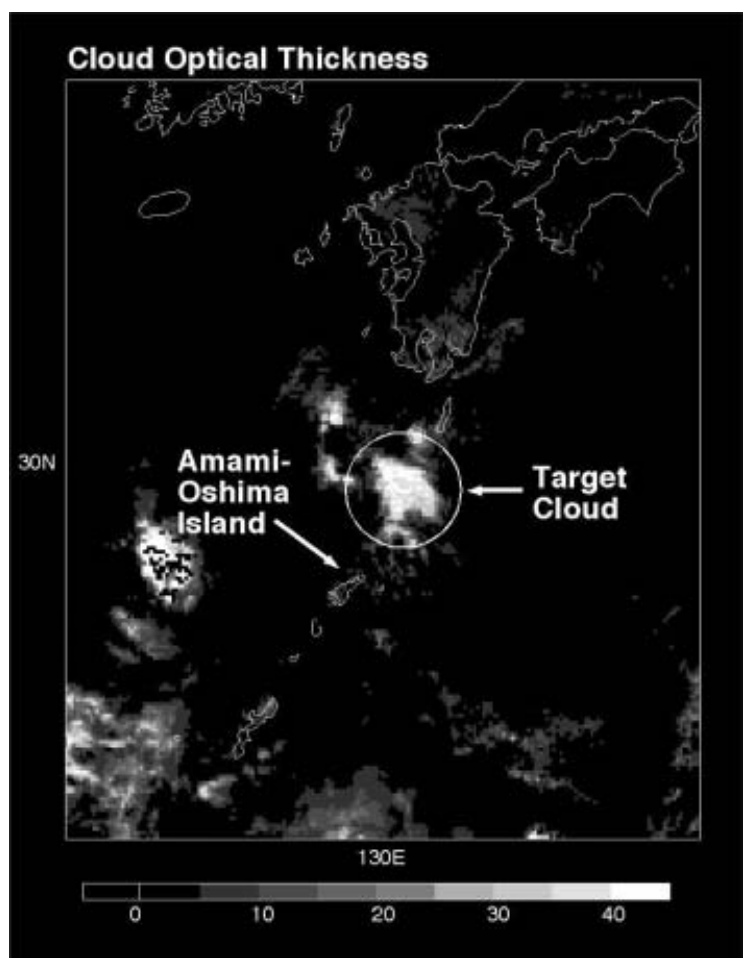

Fig. 5. Cloud optical thickness obtained from the MODIS retrieval. The B200 took off at 00:34:00 UTC reached the cloud area at 01:30:00 UTC and started observing the target stratocumulus clouds.

[Fig. 6(c)], thus the MODIS remote-sensed effective radii at the other time are expected to be correct. The target cloud seemed to be divided into two major different systems, $\mathrm{A}$ and $\mathrm{B}$ during the in-cloud flight by the B200. For cloud system A (02:18:00-02:19:45), the cloud optical thickness by MODIS $\tau_{c_{-} \text {modis }}$ gradually and smoothly increased from 40.5 to 42.7 then decreased to 41.0 along the flight track of the B200. Hereafter, we named these sub-domains by A1 and A2. Since both the cloud optical thickness and cloud effective radius retrieved from the MODIS data varied smoothly, the A1 and A2 domains seemed to be categorized into the same cloud system. However, the in situ aircraft measurements showed the different cloud characteristics in A1 and A2. The cloud effective radii $r_{e_{-} f s s p}$ were constant $(=8 \mu \mathrm{m})$ with flight altitude decreasing in the A1 domain, then $r_{e_{-} f s s p}$ increased from 6 to $9 \mu \mathrm{m}$ with decreasing $\tau_{c \_ \text {modis }}$ along the flight path in the A2 domain. The A2 area corresponded to about four kilometers along the flight path (one minute flight by $70 \mathrm{~m} / \mathrm{s}$ flight speed). At just the turning point between $\mathrm{A} 1$ and $\mathrm{A} 2$, the cloud droplet concentration [Fig. 6(d)] reached the maximum value $\left(\sim 535\right.$ number $\left./ \mathrm{cm}^{3}\right)$, the cloud effective radius the minimum value $\left(r_{e_{-} f s s p} \sim\right.$ $5.3 \mu \mathrm{m})$, and the optical thickness obtained from MODIS, the maximum value ( $\tau_{c_{-} \text {modis }} \sim$ 42.5). The cloud system in the B domain is obviously different from A. $r_{e_{-} f s s p}$ smoothly decreased with decreasing altitude. $\tau_{c \_ \text {modis }}$ were almost stable in B. The cloud microphysical evolution seemed to obey the adiabatic change process in the B domain.

\section{Summary and concluding remarks}

The comparisons of the cloud properties between satellite observations, ground and aircraft measurements obtained from APEX IOP in 2000 and 2001 were performed to understand the characteristics of data obtained from each observing platform, and investigate the potentiality of synergistic use of multi platform data.

We found a moderate correlation of the liquid water path between the satellite (MODIS) observations and ground-based (WVR1100) measurements. The inhomogeneous clouds over the ground station and the different field-of-view of the measurements make the comparison difficult. Thus, we made a spatial (radius $<5 \mathrm{~km}$ ) and temporal (fifteen minutes) subsets of results obtained from MODIS and WVR1100, respectively, and calculated mean and standard deviations. It is important to acquire more data of clouds as homogeneous as possible. However, under the limitation, such as a short IOP periods and inhomogeneity of clouds in the East China Sea region, this statistical method will be the better one. It was shown that the satellite-retrieved (MODIS) cloud effective radius agreed with that from the aircraft measurements (FSSP) around the cloud top. The combined analyses of the satellite and aircraft measurements, indeed, suggested that many more information about cloud properties could be determined than by an individual analysis. One suggestion for the future IOPs is that we need more opportunities of collocated and coincident observations at the cloud top to achieve 


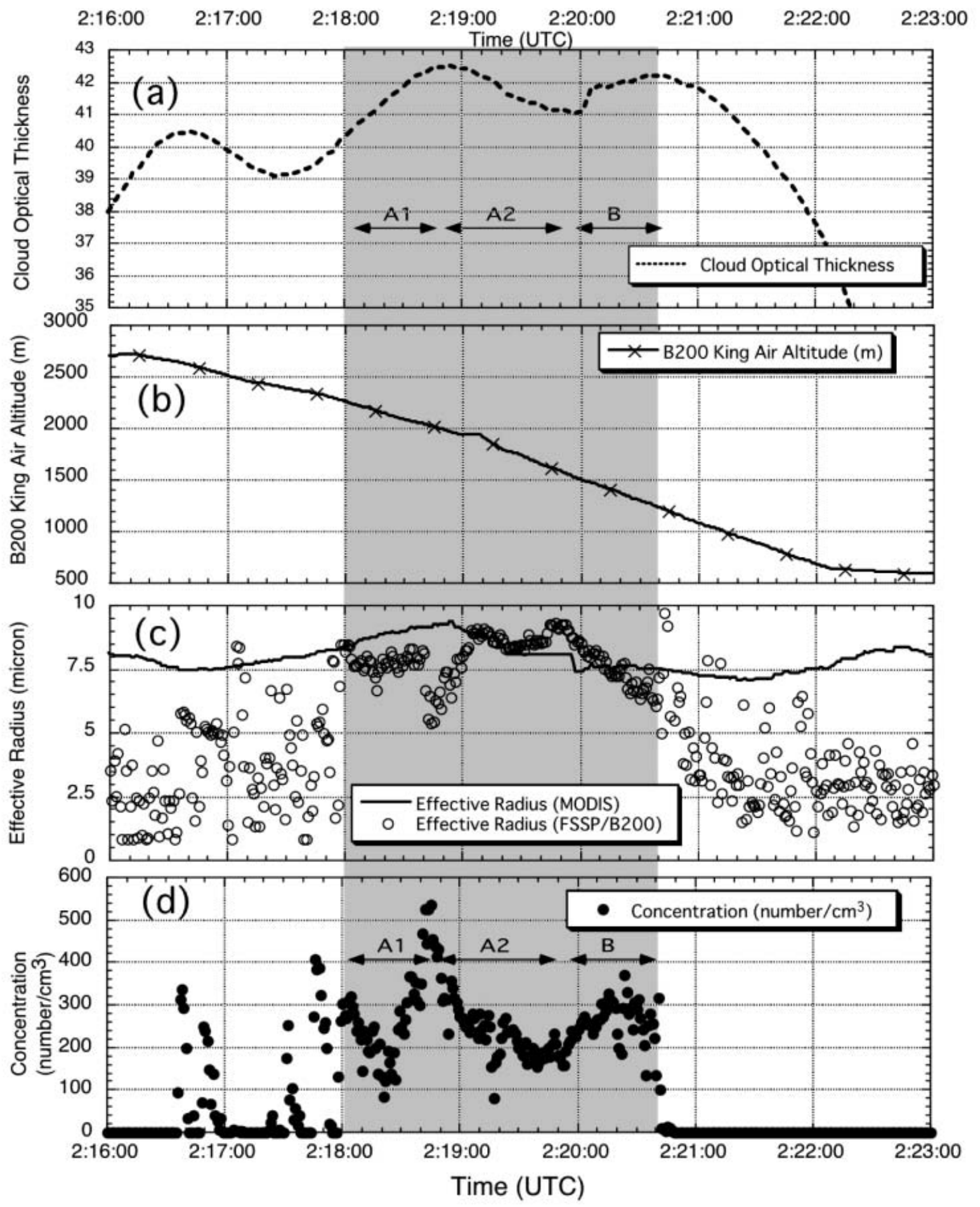

Fig. 6. Time series of the cloud in situ measured by FSSP on B200 from 02:16:00 to 02:23:00 UTC (11:16:00 to 11:23:00 JST) time domain and MODIS values of the optical thickness and effective radius at the corresponding location. (a) the cloud optical thickness obtained MODIS, (b) B200 King Air flight altitude, (c) cloud effective particle radius obtained from FSSP(dots) and MODIS(curve), (d) cloud concentration. 
fine and direct comparisons of the cloud effective radius. From this point, the horizontal flights along the cloud top are requested. In addition, the measurement of vertical structure of microphysical properties for horizontally homogeneous clouds by aircraft is interesting for validating the satellite-measured cloud effective radii. From this point, the spiral descent from the top to the bottom of the horizontally homogeneous clouds are requested. The comparisons between satellite imager and cloud radar will contribute to revealing the cloud forming and droplet evolution process in clean and turbid atmospheric conditions. This is one of the future works.

\section{Acknowledgements}

The authors are grateful to Jorgen B. Jensen of CSIRO, Akihiro Yamazaki and Hiroki Togawa of the Meteorological Research Institute for the aircraft data acquisitions and analyses, Itaru Okada of the Chiba University for the data acquisition at the Amami-Oshima ground site and data distributions, and Kentaroh Suzuki of the Center for Climate System Research, University of Tokyo, for the valuable discussions. The authors also thank Christopher Lynnes of the NASA GSFC for his great efforts to the data distribution system for MODIS data. The MODIS data were provided by NASA-MODIS/GES-DAAC. This research is supported by the CREST, Japan Science and Technology and Japan Aerospace Exploration Agency, EORC GLI Science Project (G60).

\section{References}

Coakley, J.A., R.L. Bernstein, and P.A. Durkee, 1987: Effect of ship-stack effluents on cloud reflectivity. Science, 237, 1020-1022.

Dong, X., T.P. Ackerman, and E.E. Clothiaux, 1998: Parameterizations of the microphysical and showrwave radiative properties of boundary layer stratus from ground-based measurements. J. Geophys. Res., 103(D24), 3168131693.

, P. Minnis, G.G. Mace, W.L. Smith Jr, M. Poellot, R. Marchand, and A. Rapp, 2002: Comparison of stratus cloud properties deduced from surface, GOES, and aircraft data during the March 2000 ARM Cloud IOP. J. Atmos. Sci., 58, 3265-3284.

Han, Q., R. Welch, J. Chou, W. Rossow, and A. White, 1995: Validation of satellite retrievals of cloud microphysics and liquid water path using observations from FIRE. J. Atmos. Sci., 52, 4183-4195.

Hayasaka, T., M. Kuji, and M. Tanaka, 1994: Air truth validation of cloud albedo estimated from very high resolution radiometer data. J. Geophys. Res., 99(D9), 18685-18693.

Huebert, B.J., T. Bates, P.B. Russell, G. Shi, Y.J. Kim, K. Kawamura, G. Carmichael, and T. Nakajima, 2003: An overview of ACE-Asia: Strategies for quantifying the relationships between Asian aerosols and their climatic impacts. J. Geophys. Res., 108(D23), 8633, doi:10.1029/2003JD003550.

Ichoku, C., D.A. Chu, S. Matto, Y.J. Kaufman, L.A. Remer, D. Tanre, I. Slutsker, and B.N. Holben, 2002: A spatio-temporal approach for global validation and analysis of MODIS aerosol products. Geophys. Res. Lett., 19(12), doi:10.1029/2001GL013206.

IPCC (the Intergovernmental Panel on Climate Change), 2001: Climate Change 2001: The Scientific Basis, J.T. Houghton, Y. Ding, D.J. Griggs, M. Noguer, P.J. van der Linden, D. Xiaosu, K. Maskell, and C.A. Johnson (Eds.), Cambridge Univ. Press, New York, 896 pp.

Kawamoto, K., T. Nakajima, and T.Y. Nakajima, 2001: A global determination of cloud microphysics with AVHRR remote sensing. J. Climate, 14, 2054-2068.

King, M.D., Y.J. Kaufman, W.P. Menzel, and D. Tanré, 1992: Remote sensing of cloud, aerosol, and water vapor properties from the Moderate Resolution Imaging Spectrometer (MODIS). IEEE Trans. Geosci. Remote Sens., 30, 2-27.

Kuji, M., T. Nakajima, M., and M. Tanaka, 2000: The retrieval of effective particle radius and liquid water path of low-level marine clouds from NOAA AVHRR data. J. Appl. Meteor., 39, 9991016.

Nakajima, T. and M.D. King, 1990: Determination of the optical thickness and effective raidus of clouds from reflected solar radiation measurements. Part I: Theory. J. Atmos. Sci., 47, 18781893.

-, T., M. Sekiguchi, T. Takemura, I. Uno, A. Higurashi, D. Kim, B.-J. Sohn, S.-N. Oh, T.Y. Nakajima, S. Ohta, I. Okada, T. Takamura, and K. Kawamoto, 2003: Significance of direct and indirect radiative forcings of aerosols in the East China Sea region. J. Geophys. Res., 108, doi:10.1029/2002JD00326.

Nakajima, T.Y. and T. Nakajima, 1995: Wide-area determination of cloud microphysical properties from NOAA AVHRR measurement for FIRE and ASTEX regions. J. Atmos. Sci., 52, 4043-4059. 
Platnick, S. and S. Twomey, 1994: Determining the susceptibility of cloud albedo to change in droplet concentration with the Advanced Very High Resolution Radiometer. J. Appl. Meteor., 33, 334-347.

and F.P.J. Valero, 1995: A validation of a satellite cloud retrieval during ASTEX. J. Atmos. Sci., 52, 2985-3001.

, M.D. King, S.A. Ackerman, W.P. Menzel, B.A. Baum, J.C. Riedi, and R.A. Fey, 2003: The MODIS cloud products: Algorithms and Examples form Terra. IEEE Trans. Geosci. Remote Sens., 41, 459-473.
Radke, L.F., J.A. Coakley Jr., and M.D. King, 1989: Direct and remote sensing observations of the effect of ships on clouds. Science, 246, 11461149.

Twomey, S., M. Piepgrass, and T.L. Wolfe, 1984: An assessment of the impact of pollution on global cloud albedo. Tellus, 36, 356-366.

Wolfe, R., E.M. Nishihama, A.J. Fleig, J.A. Kuyper, D.P. Roy, J.C. Storey, and F.S. Patt, 2002: Achieving subpixel geolocation accuracy in support of MODIS land science. Remote Sensing of Environment, 83, 31-49. 